Natural Hazards and Earth System Sciences, 5, 621-632, 2005

SRef-ID: 1684-9981/nhess/2005-5-621

European Geosciences Union

(C) 2005 Author(s). This work is licensed

under a Creative Commons License.

\title{
An attempt to refine rockfall hazard zoning based on the kinetic energy, frequency and fragmentation degree
}

\author{
M. Jaboyedoff ${ }^{1,2}$, J. P. Dudt ${ }^{1}$, and V. Labiouse ${ }^{1}$ \\ ${ }^{1}$ Rock Mechanics Laboratory (LMR), Swiss Federal Institute of Technology Lausanne, EPFL, 1015 Lausanne, Switzerland \\ ${ }^{2}$ Present address: Institute of Geomatics and Risk Analysis (IGAR), University of Lausanne, Switzerland
}

Received: 2 November 2004 - Revised: 4 July 2005 - Accepted: 18 July 2005 - Published: 11 August 2005

\begin{abstract}
Rockfall hazard zoning is usually achieved using a qualitative estimate of hazard, and not an absolute scale. In Switzerland, danger maps, which correspond to a hazard zoning depending on the intensity of the considered phenomenon (e.g. kinetic energy for rockfalls), are replacing hazard maps. Basically, the danger grows with the mean frequency and with the intensity of the rockfall. This principle based on intensity thresholds may also be applied to other intensity threshold values than those used in Switzerland for rockfall hazard zoning method, i.e. danger mapping.

In this paper, we explore the effect of slope geometry and rockfall frequency on the rockfall hazard zoning. First, the transition from 2D zoning to 3D zoning based on rockfall trajectory simulation is examined; then, its dependency on slope geometry is emphasized. The spatial extent of hazard zones is examined, showing that limits may vary widely depending on the rockfall frequency. This approach is especially dedicated to highly populated regions, because the hazard zoning has to be very fine in order to delineate the greatest possible territory containing acceptable risks.
\end{abstract}

\section{Introduction}

Rockfall hazard zoning for land-use planning is a complex problem, because of the different parameters involved: energy, frequency, block size, characteristics of the topography, uncertainty of all parameters, etc. Whatever the method used, zoning leads to a document that helps authorities to decide if a certain type of infrastructure or housing can be built within a certain area or if some specific human activities may be performed in some particular location.

For communication purpose the authorities need unique land-use maps implying that the risk mapping is performed using normative conditions, i.e. a building type or other facility. Because the map must be understood by the whole pop-

Correspondence to: M. Jaboyedoff

(support@quanterra.org) ulation, a complicated document such as multiple layer Geographical Information System (GIS) document is not suitable. In this respect, the Swiss federal services in charge of natural hazards have developed the concept of danger zones (Lateltin, 1997; Raetzo et al., 2002), coupling hazard zones and intensity of the natural phenomenon (total kinetic energy for rockfalls) (Fig. 1). Contrasting with risk analysis, zoning depends on a normative category of hazard defined on potential damage of buildings representing a sort of risk analysis for one hazard type, because danger zones imply degrees of damages. Even now risk analysis is still not a routine procedure for land-use planning.

Often the methods used to establish land-use planning overestimate voluntarily the hazard. These approaches are only understandable if the studied area is sparsely populated. In many countries, like Switzerland, the inhabited areas are often close to or included in hazardous zones. Thus the challenge is to estimate rockfall hazard zoning with more precision. We propose a hazard zonation called, in Switzerland, danger zonation (see below) based on the Swiss federal codes (Lateltin, 1997; Raetzo et al., 2002). These codes imply taking into consideration energy and mean return period (Fig. 1), explicitly using the frequency of historical events. That kind of danger mapping has already been proposed by Van Westen (2004) and by Calcaterra et al. (2004).

Rockfall hazard zoning is mostly performed using a relative hazard scale (Van Westen, 2004), which does not explicitly take into account time. In order to refine rockfall hazard or danger zonation, it is mandatory to use frequency of events, or at least a qualitative estimate.

The simplest way to construct a rockfall-hazard map is to estimate the entire perimeter of potential rock failure and runout with a geometrical method (Lied, 1977; Toppe, 1987; Evans and Hungr, 1993; Jaboyedoff and Labiouse, 2001, $2005^{1}$ ), assuming that a rockfall block cannot travel beyond

\footnotetext{
${ }^{1}$ Jaboyedoff, M. and Labiouse, V.: CONEFALL: a program for rapid rock-fall potential propagation zone estimation, Computers and Geosciences, submitted, 2005.
} 
Table 1. Definition of the main variables.

\begin{tabular}{ll}
\hline Symbol & Definitions \\
\hline$N_{t r}^{t o t}$ & Total number of trajectories \\
$E$ & Total kinetic energy \\
$E_{i}, E_{j}$ & Kinetic energy threshold \\
$H(E, x)$ & Hazard at a location, $x$, for a given kinetic energy \\
$l$ & Distance from the rockfall source \\
$N_{b}$ & Mean number of blocks per rock-mass-failure $\left(N_{b}=V_{i} / V_{b}\right)$ \\
$N_{t r}(m, n)$ & Number of blocks crossing the cell index $m, n$ of the indexed DEM \\
$P_{p}(E, x, t)$ & Probability of propagation for an energy, $E$, at point, $x$, for a given return period \\
$r$ & Radius in polar coordinates \\
$t_{r e f}$ & Reference period \\
$V_{b}$ & Mean block volume \\
$V_{i}$ & Volume of one rock-mass-failure \\
$w$ & Target diameter \\
$x$ & Spatial location \\
$x_{l i m}\left(t_{r e f}\right)$ & Runout distance end point: point beyond which the hazard $H\left(x_{l i m}\right)$ is lower than $1 / t_{r e f}$ \\
$x_{E i}\left(t_{r e f}\right)$ & Energy travel limit: point beyond which the hazard $H\left(x_{E i}\right)$ is lower than $1 / t_{r e f}$ for a given energy $E_{i}$ \\
$\alpha$ & Angle values of polar coordinates \\
$\lambda$ & Rock-mass-failure mean probability or frequency \\
$\theta$ & Angle of polar coordinates \\
$\rho_{f}$ & Number of events per unit of length of cliff \\
\hline
\end{tabular}

\section{Return period or mean probability}

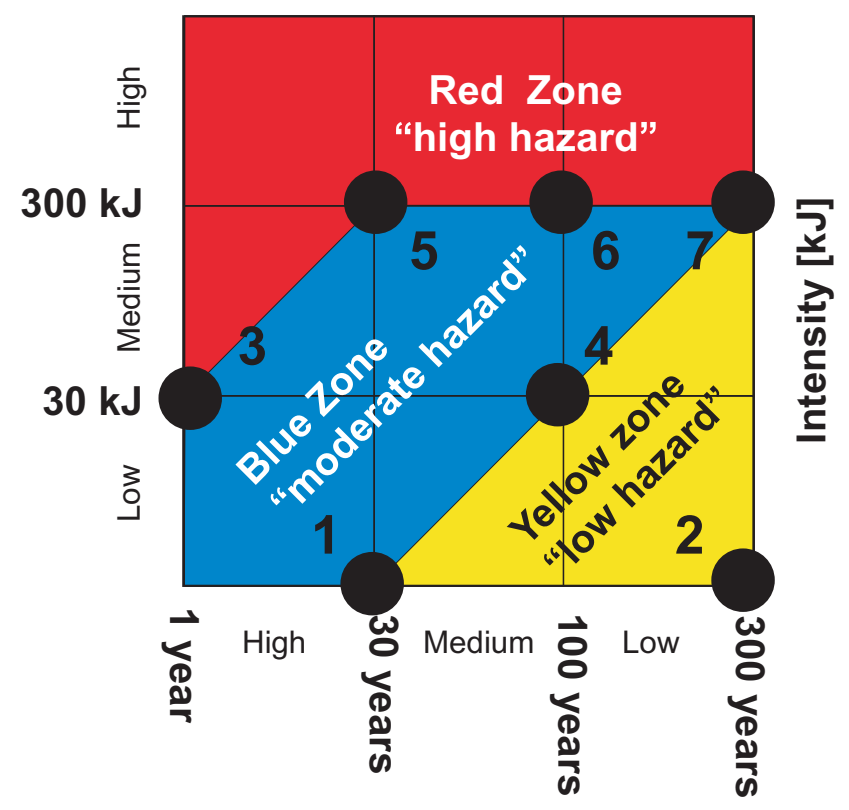

Fig. 1. The chart used to define the danger, according to the Swiss codes, is based on the return period and kinetic energy (after Lateltin, 1997; Raetzo et al., 2002). The numbered points are used to estimate the zoning with three colours: yellow, blue and red, corresponding to "low", "moderate" and "high" danger. The danger is considered as high for return periods below 300 years and energies above $300 \mathrm{~kJ}$. The danger is lowered with both decreasing energy and increasing return period.

a point defined by the intersection of the topography with a cone starting from the cliff making a fixed angle with the horizon (=shadow angle; see on Fig. 2).
Many methods dedicated to land-use planning and using rockfall simulations (trajectory analysis) are based on the number of blocks reaching a point or a target weighted by a relative frequency of rock failure (Rouiller et al., 1998; Besson et al., 1999; Manche, 2000; Baillifard et al., 2001; Mazzoccola, 2001; Mazzoccola and Sciesa, 2001). Energy is also taken into account. Following the same principle, Guzzetti and Crosta (2001) have developed a hazardzonation method taking into account: maximum velocity, maximum bounce height, number of trajectories and energy using a rockfall simulation program STONE linked to GIS (Guzzetti et al., 2002).

Hazard can also be inferred from direct observations of rockfalls (Bunce et al., 1997). However, this approach is usually dedicated to linear facilities such as communication routes (Baillifard et al., 2004).

Following the Swiss hazard-zonation (Lateltin, 1997; Raetzo et al., 2002), it is possible to map-delineate zones of low, medium and high danger (Jaboyedoff and Labiouse, 2002). This zoning depends on the topography, the frequency of rock failure and the reference period considered (see below) as well as the code used for rockfall simulation and it assumes a target of fixed size, because a block is more likely to hit a larger object. Please see Table 1 for meaning of variables used below.

\section{Rockfall hazard}

The rockfall process can be divided into two parts; the first is the rock instability or failure in the source area and the second is the runout area at a distance (Fig. 2). The hazard $(H(E, x))$ at a point, $x$, for a given kinetic energy, $E$, is given 
by the product of the rock-mass-failure mean probability or frequency, $\lambda_{f}$, and the probability of propagation up to $x, P_{p}$ (Leroi, 1996; Jaboyedoff et al., 2001):

$H(E, x)=\lambda_{f} \times P_{p}(E, x)$

$H(E)$ can be estimated for different energies. $\lambda_{f}$ may depend on block volume (mass), i.e. on $E$ (Table 1). In the following we will use $\lambda_{f}$ alone, keeping in mind that it can be energy dependent, because rockfall frequency can change owing to the considered entire instability volume. Usually larger instabilities are considered as less frequent, but blocks can be bigger and energy higher (Vengeon et al., 2001).

\subsection{Probability of failure (frequency)}

A complete characterisation of an unstable rock-mass must lead to the estimation of the mean probability of failure, which corresponds to a mean frequency of the occurrence of rock fall events, $\lambda_{f}$. This value is necessary for risk analysis, even if the scale is relative. It can be inferred from historical catalogues (Bunce et al., 1997; Wieczorek et al., 1998; Vengeon et al., 2001; Pauly and Payany, 2002) estimating the probability of occurrence of rockfall in areas or along a linear object such as a communication facility.

Other methods estimate the probability of failure using a relative rock failure rating system (Cancelli and Crosta, 1993; Mazzoccola and Hudson, 1996; Rouiller et al., 1998). Implicitly, mean frequency is behind all such rating systems.

Depending on the knowledge of the instabilities, the frequency can be either applied directly to a particular instability or to a whole slope.

\subsection{Probability of propagation}

The probability of propagation, $P_{p}$, is dependent on the topography, the characteristics of the outcropping lithology along the path of the block, the block shape, material and mass. This probability can be estimated by field observation and isopleths (Sasaki et al., 2002), and/or by rockfall simulations (Hoek, 2000; Guzzetti et al., 2002).

The simplest way to assess $P_{p}$ is to calculate the percentage of all simulated trajectories that cross a point (2D) or an area (3D) (Crosta et al., 2001; Guzzetti et al., 2002). For instance if 60 of 1000 trajectories cross a point, then $P_{p}=6 \%$, and if $\lambda_{f}=0.05$ event per year, then $H=3 \times 10^{-3}$ event by year.

\section{Rockfall hazard or danger zoning after the Swiss codes}

Usually risk is determined by multiplying hazard by vulnerability and cost (Leroi, 1996). This procedure is still not a routine approach for land-use planning. In some countries like Switzerland, the mapping method used for land-use planning procedure generates a "danger map" (Raetzo et al., 2002). The map is based on a mean probability-intensity diagram. The intensity is defined as the total kinetic energy, i.e. the

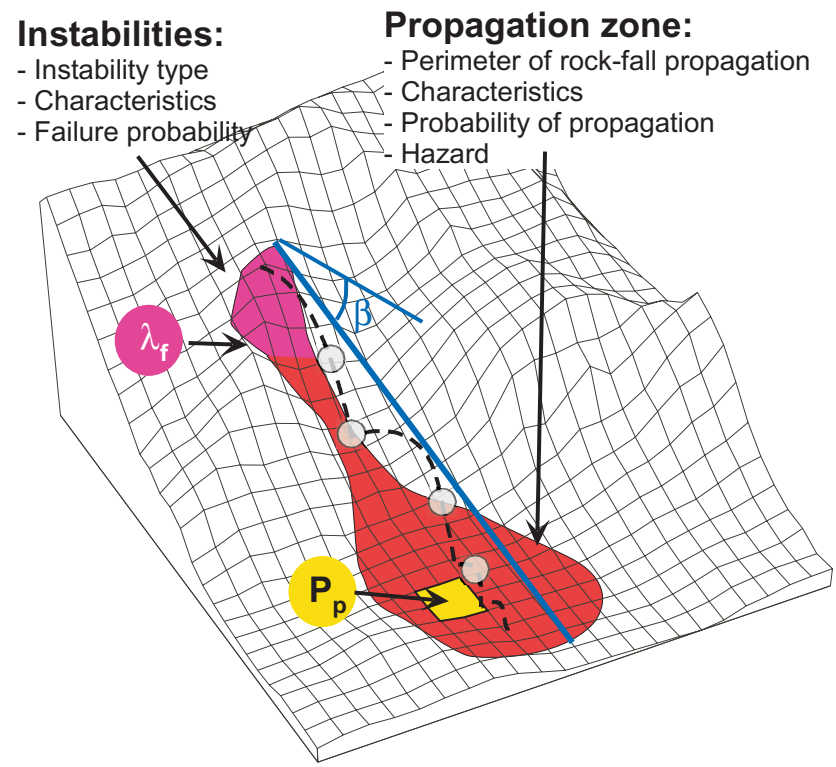

Fig. 2. Rockfall process and hazard evaluation (after Jaboyedoff et al., 2001). $\lambda_{f}$ is the rock-mass-failure mean frequency and $P_{p}$ the probability of propagation up to the yellow area. In blue the shadow angle $(\beta)$ principle is shown

sum of both rotational and translational energies. The higher the intensity and/or the higher the mean probability of event, the higher is the degree of danger (Fig. 1). Incidentally danger classes are also used for other hazards such as floods, snow avalanches, landslides, etc., albeit these use different intensity scales than for rockfall events (Raetzo et al., 2002).

For rockfalls, the Swiss codes (Lateltin, 1997) state that the mean probability of occurrence or return period are considered as "high" if more than one event occurs in 30 years, "medium" if the return period is between 30 and 100 years and, "low" if it is between 100 and 300 years, and is assumed "nil" if it is over 300 years, except for large catastrophic rockfalls or rock avalanches. Intensity is classified as "low" for rockfalls of kinetic energy $(E)$ less than $30 \mathrm{~kJ}$, "medium" for E between 30 and $300 \mathrm{~kJ}$, and "high" if $E$ is greater than $300 \mathrm{~kJ}$. These limits are designed to delineate build-up and protection measures for buildings. $30 \mathrm{~kJ}$ corresponds to the resistance of an oak-wood stiff barrier and $300 \mathrm{~kJ}$ corresponds to the resistance of a reinforced concrete wall (Raetzo et al., 2002). The danger zones are defined as follow (Fig. 1):

"High danger" zone, (also called "Red zone"): A rockfall area including potential rockfall with higher energy than $300 \mathrm{~kJ}$ and with a mean frequency of more than 1 event every 300 years. Areas with potential rockfalls with energy greater than $30 \mathrm{~kJ}$ and mean frequency above 1 event by 30 years (point 3 in Fig. 1) are also red zones. People are mainly at risk outside buildings. A rapid destruction of the buildings is possible.

"Moderate danger" (Blue zone): the energy of the potential rockfalls is less than $300 \mathrm{~kJ}$ (points 5, 6 and 7 in Fig. 1); for high frequencies, energy below $30 \mathrm{~kJ}$; for low frequencies 


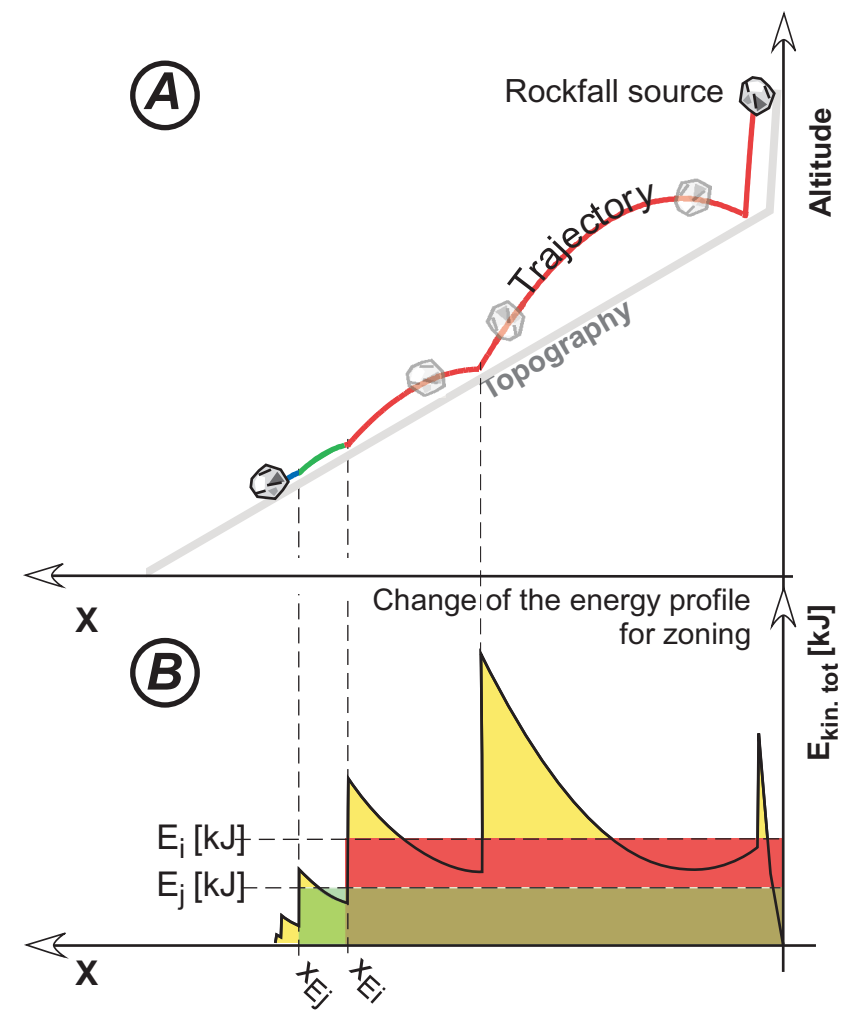

Fig. 3. Schematic example of one rockfall trajectory and its total energy ( $\left.E_{\text {tot }}\right)$ distribution. (a) Trajectory itself. (b) The energy travel limits $\left(X_{E i}, X_{E j}\right)$ are the last points where a block crosses the energy thresholds assuming $E_{i}>E_{j}$. The profiles of energy are transformed in rectangles, which means that the energies of blocks are not considered below the energy travel limits (because their energy will never reach again the threshold) and are equal or greater than the energy thresholds above the energy travel limit.

(above 1 event for 100 years), energy between 30 and $300 \mathrm{~kJ}$. People are at risk of injury outside buildings, but the risk is considerably lower inside buildings. Damage to buildings should be expected if no reinforcement exists.

"Low danger" (Yellow zone): Expected energy is below $30 \mathrm{~kJ}$ for a 100 years return period and $300 \mathrm{~kJ}$ for a 300 years return period (points 1, 4, and 7 on Fig. 1). Any rockfall with a return period ranging from 30 to 300 years presents at least a low danger. People are at slight risk of injuries outside buildings. Slight damage of building is expected.

A "yellow hatched zone" with "Residual danger" is also defined. It covers areas where large catastrophic landslides are suspected, even if the return period is over 300 years. This zone is not represented on Fig. 1.

The above danger categories may be adapted to other limits than 30 and $300 \mathrm{~kJ}$ and 30, 100, 300 years depending on the objectives of land-use planning. The presented method is a generalisation of the Swiss danger mapping method: one return period value and one intensity threshold can define a danger limit. It can represent a pre-risk map for a particular edifice or a portion of infrastructure.

\section{Interpretation of rockfall simulations in 2D}

\subsection{Distribution of rockfall runout end points}

In two dimensional rockfall simulations, each point of the $\mathrm{x}$ axis (Fig. 3a) can be characterized by the distributions of the total kinetic energy, of the translational kinetic energy and the rotational kinetic energy, the masses, the bounce height, etc. The results of rockfalls modelling can also be represented as a cumulative curve of runout end points counted from the bottom of the slope. Each point of the curve indicates the percentage of blocks that reached or travelled beyond a given location, $x . P_{p}(x)$ is thus inferred from the cumulative distribution.

\subsection{Hazard}

The hazard at a point, $x$, is given by multiplying $P_{p}(x)$ by the mean number of blocks, $N_{b}$, involved in one event and by its frequency $\lambda_{f}$ (Table 1). Thus $H(x)$ is given by:

$H(x)=\lambda_{f} \cdot N_{b} \cdot P_{p}(x)$

Now consider a reference period, $t_{\text {ref }}$, as a time-limit and $x_{\text {lim }}\left(t_{\text {ref }}\right)$ the location beyond which the hazard is lower than $H\left(x_{\text {lim }}\right)=1 / t_{\text {ref }}$. Using Eq. (2), the corresponding probability that a block propagates beyond, within the reference period, is given by:

$P_{p}\left(x_{\lim }\left(t_{r e f}\right)\right)=\frac{1}{\lambda_{f} \cdot t_{r e f} \cdot N_{b}}$

In two dimensions, $x_{\text {lim }}$ can be located using the rockfall runout distribution inferred from field data and/or from simulations.

4.3 Distribution of rockfall fragments using an energy threshold

Hazard zonation can be associated with an energy threshold $E_{i}$ of the rockfall fragments. Consider the point $x_{E i}$ (energy travel limit) of a trajectory beyond which $E_{i}$ is not reached again. For a more consistent hazard zoning it is assumed that the energy threshold $E_{i}$ is reached at all points, $x$, above the energy travel limit $x_{E i}$ (Fig. 3). This hypothesis is stated to avoid inverse zonation, i.e. lower hazard in the upper part of the slope, because the energy in the upper part of the travel can be lower than below. This option is chosen to avoid misinterpretation by stakeholders who are not specialists and could hardly understand that hazard can be lower below the instability than far below it. Note that if two kinetic energy thresholds are chosen $E_{i}$ and $E_{j}$, respecting $E_{i}>E_{j}$ we have always the relationship $P_{p}\left(E_{i}, x\right) \leq P_{p}\left(E_{j}, x\right)$ (Fig. 3b).

Thus, replacing the travel limit $x_{l i m}\left(t_{r e f}\right)$ by $x_{E i}\left(t_{r e f}\right)$, the corresponding probability that a block exceeds the energy threshold $E_{i}$, within the reference period $t_{r e f}$, is given by:

$P_{p}\left(E_{i}, x_{E i}\left(t_{r e f}\right)\right)=\frac{1}{\lambda_{f} \cdot t_{r e f} \cdot N_{b}}$ 
(A)

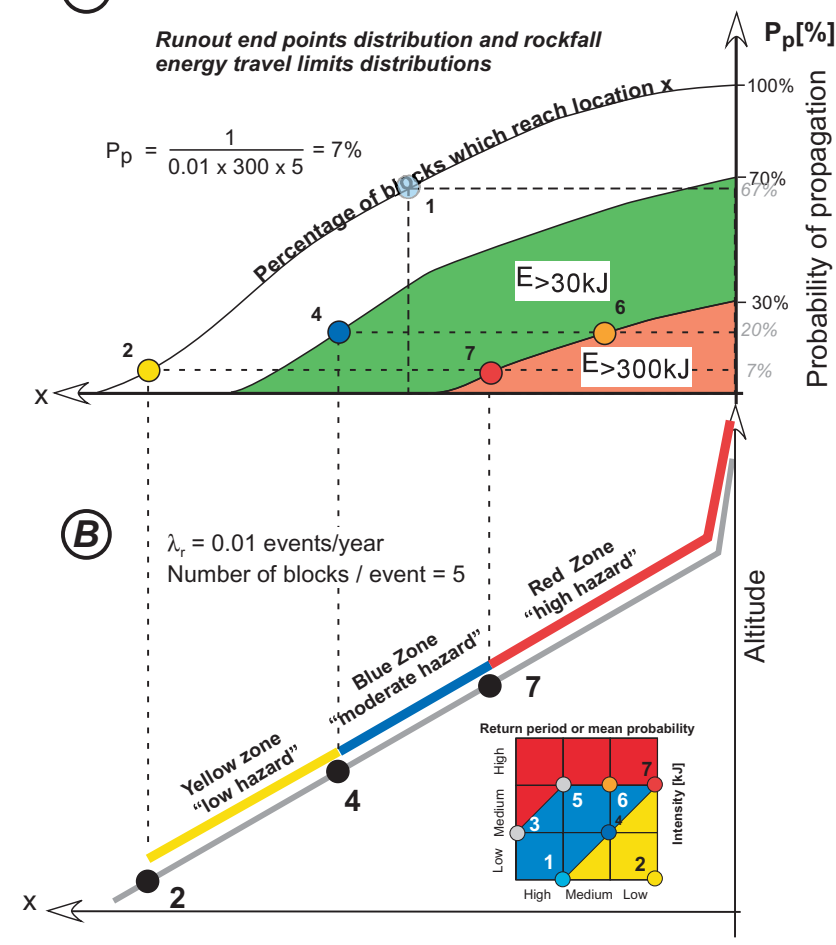

Fig. 4. (a) Synthetic example of runout end point distribution, three energy travel limits distributions (colours green and red correspond to the example of Fig. 3), respectively, 0, 30 and $300 \mathrm{~kJ}$. (b) The results are based on 1 event of 5 blocks every 100 years on average. The choice of the relevant limiting points used to define danger zones is based on Eqs. (3) and (4) using runout energy limits distributions giving $P_{p}$ of (a).

$P_{p}\left(x_{\text {lim }}\left(t_{r e f}\right)\right)$ and $P_{p}\left(E_{i}, x_{E i}\left(t_{r e f}\right)\right)$ have the same form and value, but $x_{l i m}$ and $x_{E i}$ are different because $P_{p}(x)$ and the probability of propagation for an energy travel limit $P_{p}\left(E_{i}, x\right)$ are different. $x_{l i m}$ and $x_{E i}$ are different because they correspond to the same value $\left(1 / \lambda_{f} t_{\text {ref }} N_{b}\right)$ of two different functions $P_{p}(x)$ and $P_{p}\left(E_{i}, x\right)$, as shown on Fig. 4 a.

\section{$4.4 \quad 2 \mathrm{D}$ zoning}

Using the combinations of $E$ and $t_{r e f}$ defined by the limits in the Figs. 1 and $4, P_{p}\left(x_{\text {lim }}\left(t_{r e f}\right)\right)$ and $P_{p}\left(E_{i}, x_{E i}\left(t_{r e f}\right)\right)$ are estimated. The $0 \mathrm{~kJ}$ limits are obtained using $P_{p}\left(x_{\text {lim }}\left(t_{\text {ref }}\right)\right)$ with $t_{\text {ref }}=300$ years, i.e. the point 1 , Fig. 1 . The blue and red limits are traced using the most unfavourable points of the hazard limits among points 1 and 4 . The points are obtained from each energy travel limit probability of propagation curve (Fig. 4a). The final result is obtained by inspecting points numbered 1 to 7 in Fig. 1 choosing the most unfavourable case for each limit (Fig. 4b).

\section{Pseudo 3D zoning: synthetic examples}

2D zoning is not directly applicable to reality, because nature is three dimensional. The probability that a topographical

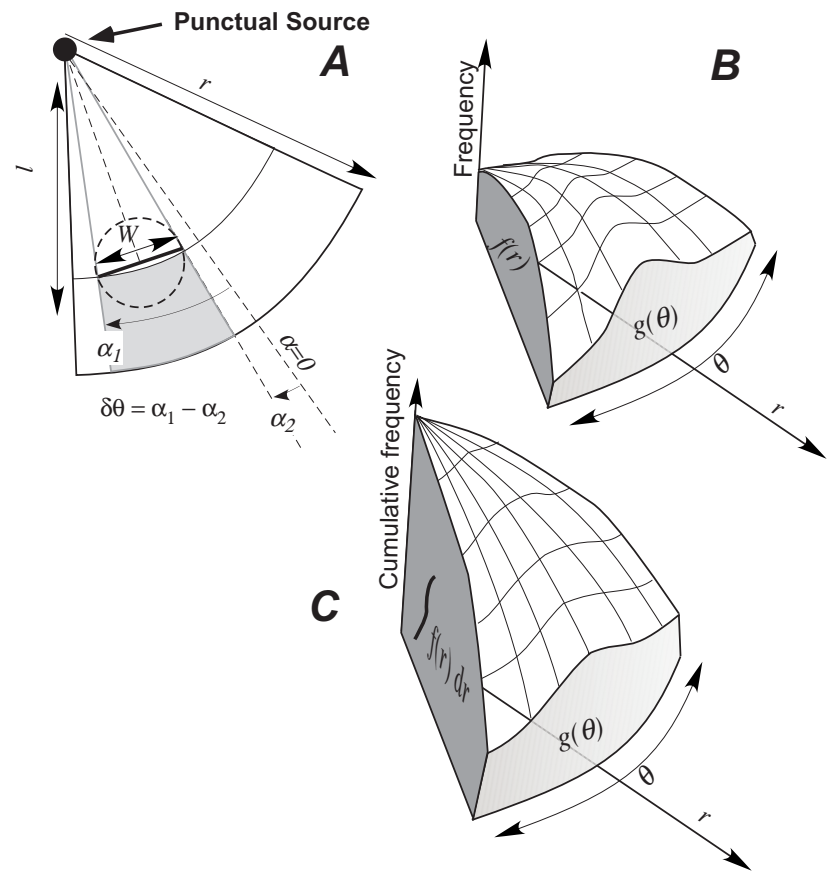

Fig. 5. Distribution of blocks in polar coordinates. Polar coordinate and relationship with a target with a diameter $w$ and $\alpha_{1}$ and $\alpha_{2}$ the angle limit of the target viewed from the punctual source (a). Synthetic stop point distribution, in 3D based on radial $(r)$ and angular distribution $(\theta)$ of runout end point of blocks (b). Cumulative distribution runout end point of indicating the percentage of blocks that reach a point $(\mathbf{c})$

point will be reached by a block modelled by a point is almost zero everywhere. It is clear that $P_{p}$ is dependent on the size of the block and/or the size of the target (Roberds, 2005). In the present case we assume a target of constant size in all directions. The block diameter may be simply added to the target dimension.

Two different ideal geometries can be distinguished: an unstable area comparable to a point source, and a linear cliff. Knowing $P_{p}$ for different energy thresholds, the procedure explained in the previous section and illustrated in Figs. 3 and 4 may be applied; the following explanation presents the method of estimating $P_{p}$.

\subsection{Point sources}

When an instability can be reduced to a point source (Fig. 5), the probability of propagation can be calculated in polar coordinates assuming rectilinear trajectories along radial trajectories, where $r$ is the radial coordinate and $\theta$ the angular coordinate, taken horizontally. If $w$ is the target diameter plus the block diameter (for reduction, the target is assumed to be a vertical cylinder) and it is located at a distance $l$ from the point source, the angular range $2 \times \delta \theta$ is given by:

$\delta \theta=\arcsin \left(\frac{w}{2 l}\right)$ 

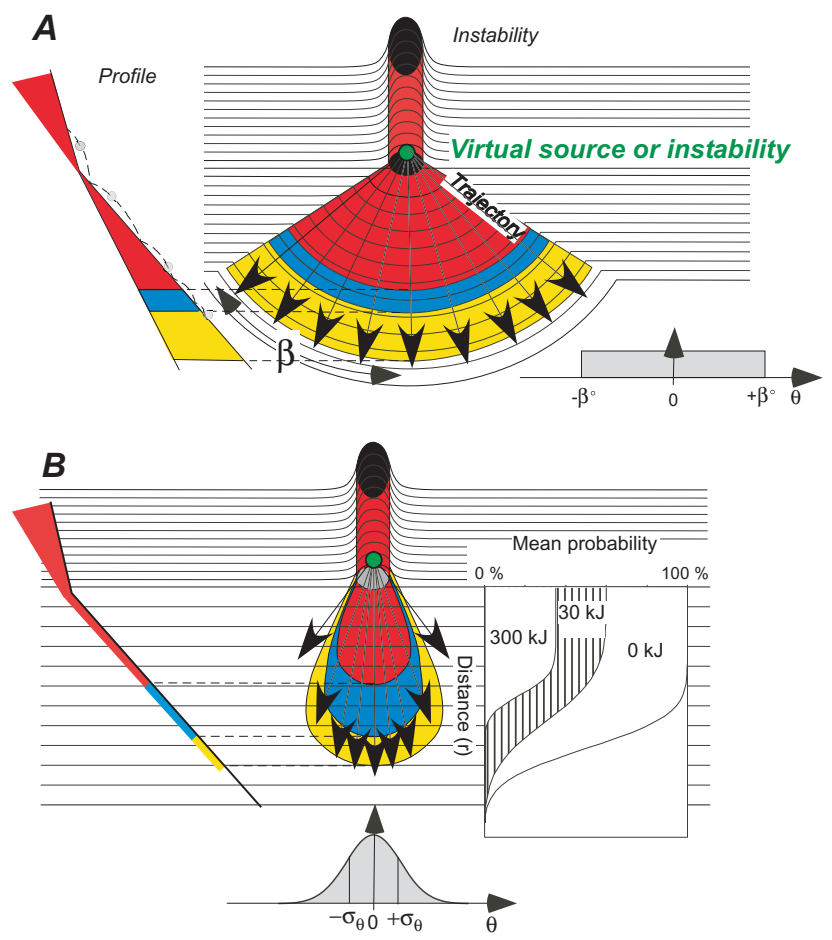

Fig. 6. Schematic example of hazard zoning for conic and planar topography. The radial distribution energy travel limit $f(r)$, for the mean frequency $\lambda_{f}$ and the target diameter $w$ are identical for both cases: uniform distribution $g(\theta)=$ constant (a) and gaussian distribution with standard deviation: $\sigma_{\theta}=7^{\circ}$ (b). The energy must be computed from the true instability.

Putting $f_{E i}(r, \theta)$ the distribution of energy travel limit, depending on $\theta$, and $g(\theta)$ the angular distribution of trajectories (we assume that $g(\theta)$ is not energy dependent), the probability to reach the target centred in $r=l$ and $\theta=\alpha$ with an energy higher or equal to $E_{i}$ is given by:

$P_{p}\left(E_{i}, \alpha, \delta \theta, l\right)=\int_{\alpha-\delta \theta}^{\alpha+\delta \theta} \int_{l}^{\infty} f_{E i}(r, \theta) g(\theta) d r d \theta$

with the condition

$\int_{+\pi}^{-\pi} \int_{0}^{\infty} f_{E i}(r, \theta) g(\theta) d r d \theta=1$

Now we assume that $\lambda_{f}$ is defined for the entire instability. As a consequence, if a channel exists below the source area, a virtual source area with the same $\lambda_{f}$ can be placed at the bottom of the channel, because all rockfalls will travel within the channel (Fig. 6).

For simple topographic surfaces, $f_{E i}(r, \theta)$ can be replaced by $f_{E i}(r) . f(r)$ can have any form like a normal distribution located around the mean energy travel limit, or other. $g(\theta)$ can be assumed to be symmetric if the topography is symmetric. If the instability or the virtual source is located at the top of a circular scree fan, there is no preferential orientation for trajectories, because all directions have the same

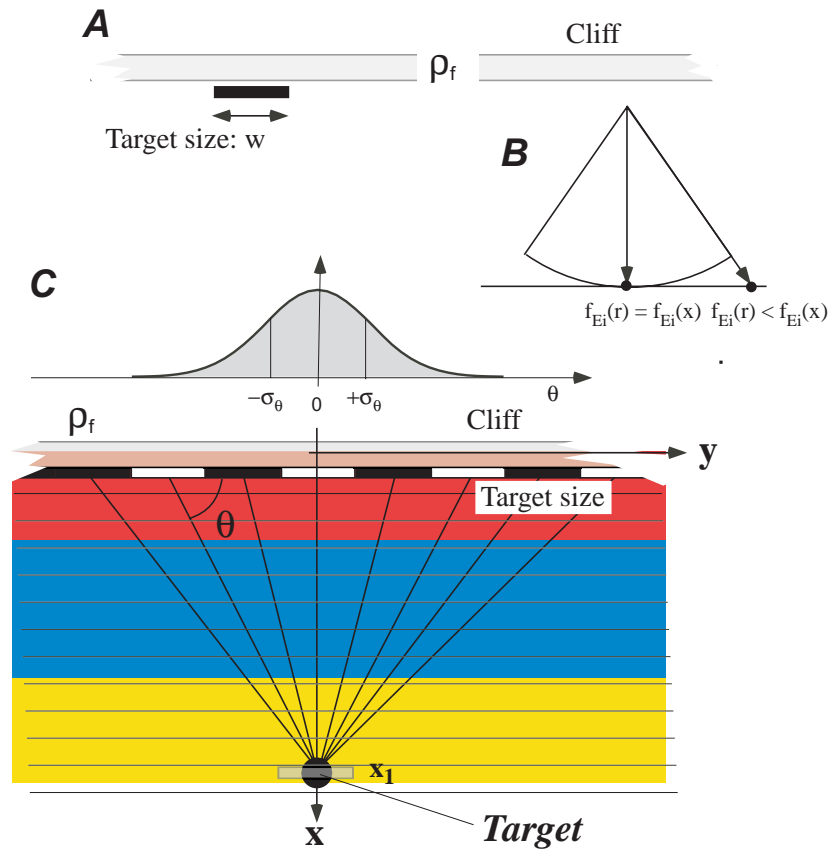

Fig. 7. Simplification used for hazard zoning below an infinite linear cliff. (a) Cliff and its frequency of rockfall per unit of length $\rho_{f}$ and the target size $w$. (b) Explanation of how the simplification of the calculation is performed. Potential trajectories starting from the cliff of blocks that can reach point in $x_{1}$. The probability of reaching point $y_{1}$ is equivalent to the probability of reaching any point at distance $x_{1}$ below the cliff from one point. (c) The results are zones parallel to the cliff assuming a source for which $\lambda_{f}=w \times \rho_{f}$ and propagation along $x$ equivalent to the $2 \mathrm{D}$ distribution.

slope angle, so that $g(\theta)$ is uniform (Fig. 6a). In the case of a virtual source (Fig. 6a), the instability is linked to the scree fan by a channel. On one hand the trajectories will be slightly concentrated in the direction of the channel because of an inertial effect, and on the other hand the variation of orientation trajectories within the channel will induce a random direction at the top of the scree, thus the assumption of no preferential orientation is correct. If a planar topography exists, the trajectories will be distributed around the dip of the slope (Fig. 6b). As a consequence $g(\theta)$ can be assumed as a normal distribution with respect to $\theta$ (Feynman et al., 1963). In this case, trajectories and their impact points are considered as random with respect to $\theta$.

\subsection{Infinite linear cliff}

Assume an infinite linear cliff with a planar sloping topography below (Fig. 7), $y$ is parallel to the cliff and, $x$ is perpendicular to it and $\lambda_{f}$ is replaced by the number of events per unit of length of cliff $\rho_{f}$. Considering an object of width $w$ (plus the block diameter) parallel to the cliff, the corresponding $\lambda_{f}$ is given by:

$\lambda_{f}=w \times \rho_{f}$

The probability of propagation to a point below a linear cliff is obtained by the integration of Eq. (6) over the range 
$\theta=[-\pi / 2 ;+\pi / 2]$, assuming that $l$ depends on $\theta$, because theoretically all points of the cliff can contribute to rockfall in one location. But as in reality trajectories are close to the dip direction, the standard deviation of the angular distribution $\sigma_{\theta}$ is small compared to $\pi / 2$, Fig. 7c). As a consequence, the radial probability $f_{E i}(r, \theta)$ can be replaced by $f_{E i}(x) \approx f_{E i}(r, \theta=0)$ with $x=r$ in the $x$ direction. This leads to $f_{E i}\left(x_{1}, \theta\right)=f_{E i}\left(x_{1}\right)$ constant for all $\theta$ values for a distance $x_{1}$ from the cliff. Note that $f_{E i}\left(x_{1}\right) \geq f_{E i}(r, \theta)$ for $x_{1}=r$ and thus the above assumption overestimates $P_{p}$. The contribution of the cliff is:

$$
P_{p}\left(E_{i}, x_{1}\right) \approx f_{E i}\left(x_{1}\right) \int_{-\pi / 2}^{+\pi / 2} g(\theta) d \theta=f_{E i}\left(x_{1}\right)
$$

An object placed and centered at $x_{1}$ can be reached by a rockfall block with a trajectory that comes from all points of the cliff with the probability:

$$
H=P_{p}\left(E_{i}, x_{1}\right) \times w \times \rho_{f}
$$

The resulting danger map contains zones oriented parallel to the cliff, based on the $2 \mathrm{D}$ zoning, but replacing $\lambda_{f}$ with $w \times \rho_{f}$ in Eqs. (3) or (4).

\section{$63 D$ zoning}

The $2 \mathrm{D}$ zoning procedure can be applied to $3 \mathrm{D}$, but the procedure is slightly different because trajectories can cross each other. The location where the largest numbers of trajectories pass through is not necessarily close to the instability. Using a digital elevation model (DEM) it is possible to count the number of trajectories $N_{t r}$ crossing each cell of the DEM indexed $m, n: N_{t r}(m, n)$. The probability of propagation can be estimated by (Guzzetti et al., 2002):

$$
P_{p}(m, n)=\frac{N_{t r}(m, n)}{N_{t r}^{t o t}}
$$

where $N_{t r}^{t o t}$ is the total number of trajectories. As in 2D zonation, the section of trajectory located above the last cell to cross the threshold energy, $E_{i}$, is considered to have energies equal or greater than $E_{i}$. By analogy with Eq. (4), all the cells that have a mean probability verifying the condition:

$P_{p}\left(E_{i}, m, n, t_{r e f}\right) \geq \frac{1}{\lambda_{f} \times t_{r e f} \times N_{b}}$

are considered to belong to the degree of danger defined by the couple $E_{i}-t_{\text {ref }}$ (Fig. 8). Such a procedure must be applied to each relevant limiting point shown in Figs. 1 and 4. The most unfavorable cases must be retained to create the hazard map. Note that the target is implicitly the horizontal cell size of the DEM. A multiplying factor may be used to standardize results.

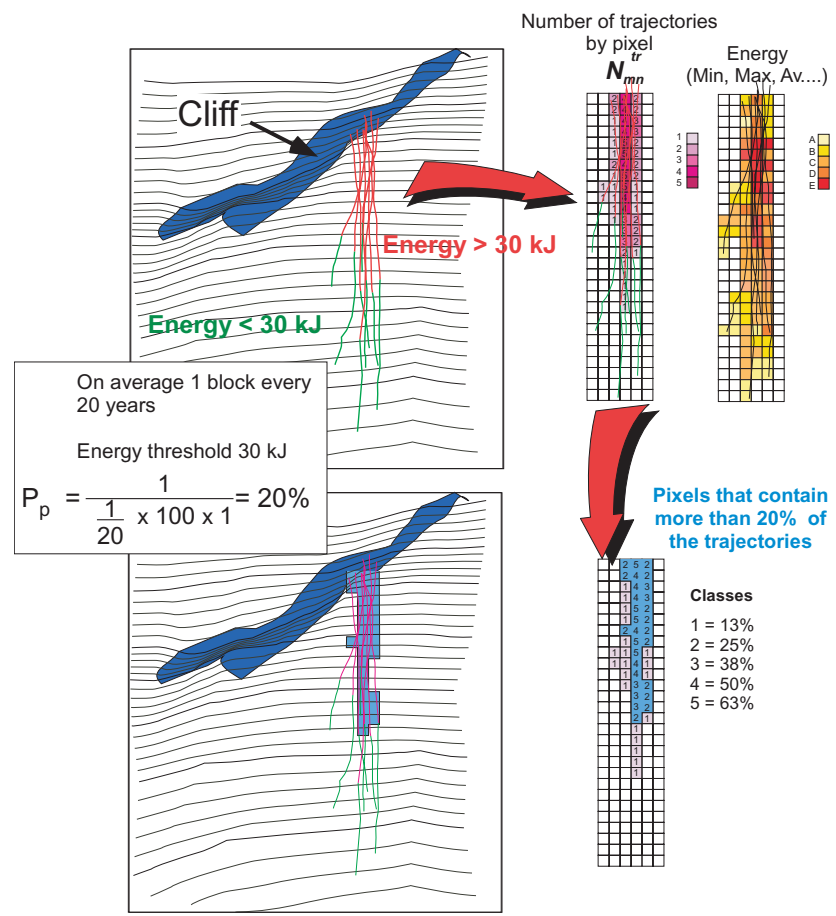

Fig. 8. Schematic example of $3 \mathrm{D}$ zoning for the blue limit using point 4 from Fig. 1 ( $t_{\text {ref }}=100$ years and $\left.E=30 \mathrm{~kJ}\right)$. The number of trajectories by pixel is used (see text). The zoning is different from energy mapping. $P_{p}$ is found using Eq. (3) with $t_{r e f}=100$ years, $\lambda_{f}=1 / 20$ years and $N_{b}=1$.

\section{Scenarios}

Unfortunately the mean rock-failure probability $\left(\lambda_{f}\right)$ is often unknown. Furthermore, the exact instability volume is also unknown. In such situations the best solution is to assess several scenarios for a danger map for different return periods for rock-failure and volumes $\left(V_{i}\right)$. We assume a fragmentation of the unstable rock mass producing a mean block size $\left(V_{b}\right)$. For a given rock mass, $P_{p}$ is modified according to Eq. (3) because $N_{b}=V_{i} / V_{b}$. Of course the block size can also be a variable. In Fig. 9, eight theoretical scenarios are compared. They are based on two $N_{b}$ and four $\lambda_{f}$ values. $\lambda_{f}$ are chosen to be the mean of the return period classes of the Swiss codes (Lateltin, 1997; Raetzo et al., 2002) of Fig. 1. The frequency variation has a greater effect on the results because the classes of frequency vary by 2 orders of magnitude, while the volume scenario variation does not exceed 2 or 3 times the estimated instability volume. For comparison, a hazard zonation only based on a propagation probability criteria of $P_{p}=10^{-4}$ (Besson, 1999) is represented. It does not depend on the mean rock-failure probability and on the number of blocks per events, and yields to a conservative zonation (large area compared to others).

As shown by various authors (Wieczoreck et al., 1998; Vengeon et al., 2001; Dussauge et al., 2003), the probability of failure is dependent on rockfall volume through an exponential law. Depending on the knowledge of $\lambda_{f}$ for a specific 


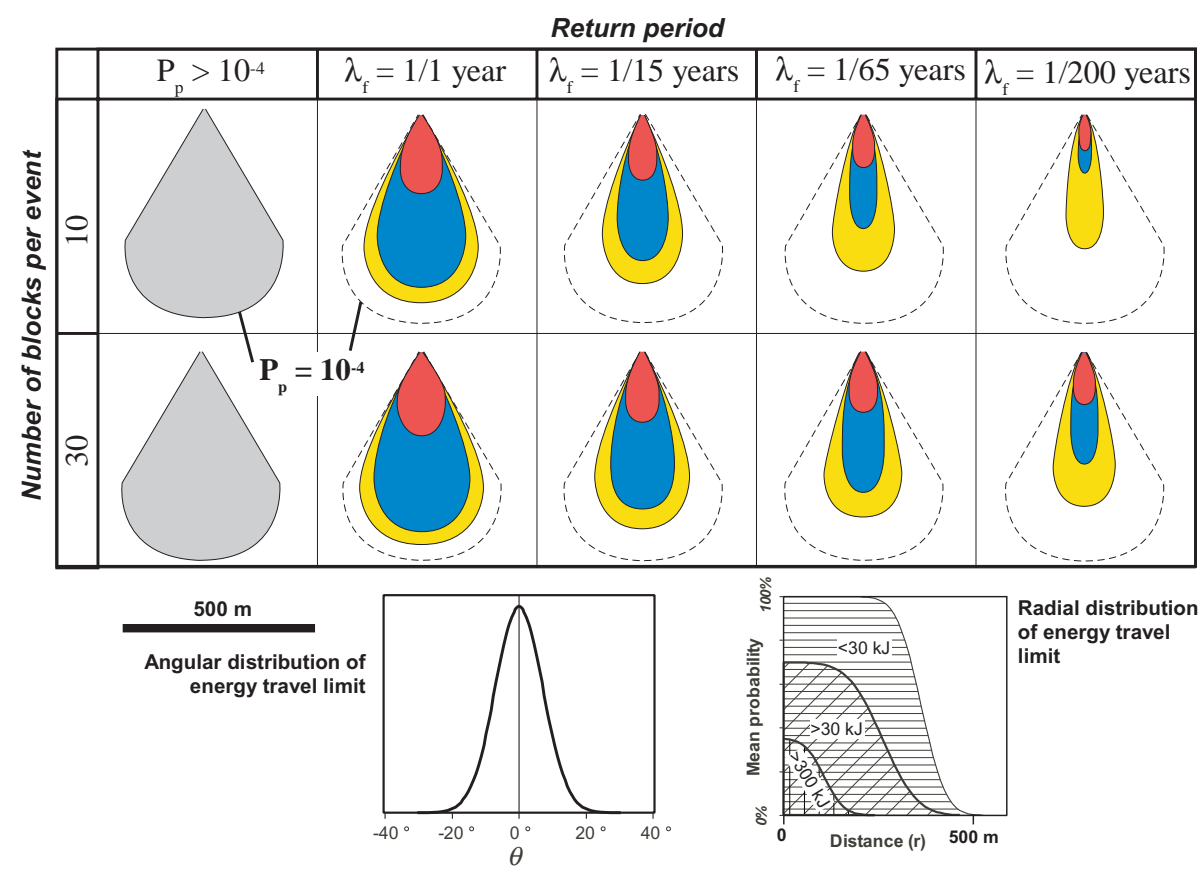

Fig. 9. Schematic examples for different frequencies $\left(\lambda_{f}\right)$ of event and number of blocks (left) on zoning of danger $($ red $=$ high; blue $=$ moderate; yellow $=$ low). The scale is indicated; the target size is $25 \mathrm{~m}$. The angular distribution is taken as a gaussian distribution with a standard deviation of $7^{\circ}$. The radial distributions are error functions. At $r=0$ energies above $30 \mathrm{~kJ}$ represent $70 \%$ of the trajectories and with energy above $300 \mathrm{~kJ}$ represent $30 \%$. The energy travel limits reached by $50 \%$ of blocks are $100 \mathrm{~m}$ for $300 \mathrm{~kJ}, 250 \mathrm{~m}$ for $30 \mathrm{~kJ}$ and $350 \mathrm{~m}$ for $0 \mathrm{~kJ}$. The left column indicates a zoning based on propagation only with a $P_{p}=10^{-4}$ (Besson et al., 1999); this limit is reported on other danger contours as a dashed contour.

instability, that law can also be used to establish different scenarios.

\section{Multi zone problems}

If propagation areas arising from several instabilities overlap, or if instabilities are imbricated, the results of the zoning are affected. The rockfall hazards from each source have to be summed for energy thresholds. Using Eq. (2), the hazard at a point $x, y$ for an energy greater or equal to $E_{i}$ linked to the instability $k$ is given by:

$H^{k}\left(E_{i}, x, y\right)=\lambda_{f}^{k} \cdot N_{b}^{k} \cdot P_{f}^{k}\left(E_{i}, x, y\right)$

For $n$ instabilities, the hazard is given by:

$H\left(E_{i}, x, y\right)=\sum_{k=1}^{n} \lambda_{f}^{k} \cdot N_{b}^{k} \cdot P_{f}^{k}\left(E_{i}, x, y\right)$

For a given period of reference $t_{r e f}$, the return period of the rockfalls is less than $t_{r e f}$ if the condition:

$H\left(E_{i}, x, y\right)>\frac{1}{t_{\text {ref }}}$

is verified. Figure 10 shows a schematic example of the effect of a diffuse instability zone on two localized instabilities. The danger zones overlap markedly below them.

\section{Case study of the Crétaux (Switzerland)}

In August 1985, a rockfall occurred near Sion, Switzerland (Descoeudres, 1990; Rouiller, 1990). Blocks fell from $1400 \mathrm{~m}$ altitude to $450 \mathrm{~m}$. Approximately fifty blocks with masses ranging from $100 \mathrm{~kg}$ to $100 \mathrm{t}$ with an average of $10 \mathrm{t}$ reached the vineyard below the instability in the valley. Since that initial rockfall, approximately $800000 \mathrm{~m}^{3}$ have fallen to the Rhône valley. Various trajectory studies have been carried out using the 3D rockfall simulation code EBOUL (Descoeudres and Zimmerman, 1987; Dudt and Heidenreich, 2001).

The zoning of danger is based on "EBOUL" simulations using a block mass ranging from 2500 to $4000 \mathrm{~kg}$, distributed homogeneously in this range (Dudt and Heidenreich, 2001). Initially the blocks fall from a $3 \mathrm{~m}$ height. The source point of blocks is located above the scree in a rectangular area measuring $7200 \mathrm{~m}^{2}$ (Fig. 11), and the rock failures are distributed homogeneously over that area. Twenty thousand trajectories were simulated. The grid mesh size of the DEM used is $25 \mathrm{~m} \times 25 \mathrm{~m}$.

The map of the simulation results of les Crétaux can be compared roughly to a circular scree fan (Fig. 6a), the trajectories having equal probability to be distributed around the axis of the scree fan, because the effect of the morphology on trajectories diminish the inertial effect of blocks. The coloured categories of Fig. 11 indicate the limits $N_{t r}>0$, 
$N_{t r}>67$ and $N_{t r}>200$. These limits correspond respectively to the perimeters of potential block runout, the high hazard zone (red zone) for 300 years return period and 1 block per year (Fig. 12b) and $1 \%$ block trajectories. The zoning in Fig. 12 is performed using $t_{\text {ref }}$ according to the colours of Fig. 1. The three results of Fig. 12 display only a red zone, because the size of the cells of DEM is greater than the distance covered by the blocks to changes their kinetic energy from $300 \mathrm{~kJ}$ to $0 \mathrm{~kJ}$, thus yellow and blue zones are too narrow to be observed.

The results of the simulation are in general agreement with the observed rockfall runout limits. Note that blocks are stopped in the scree deposit, which is in accordance with the deposit zone indexed by Rouiller (1990). Figure 12 displays three different zoning scenarios following the Swiss codes (Lateltin et al., 1997; Raetzo et al., 2002) based on 20000 3D simulated trajectories. Case (A) for which $\lambda_{f}=1 / 20$ and $N_{b}=50$ corresponds to an unfavourable case assuming an event of 50 blocks each 20 years (last event is 18 years old). The red zone occupies most of the cone. In this case a cone is suitable to simulate the runout zone. (B) $\lambda_{f}=1$ and $N_{b}=1$ is based on an annual activity. It must be remembered that zoning corresponds to a 300 years return period because of the large blocks volume. The land-use planning corresponding to this limit is defined by a red dashed line, or it can be slightly reduced if the ramifications of the red zone obtained directly from trajectories are not all considered.; (C) $\lambda_{f}=0.5$ and $N_{b}=1$ results show the dependency of zoning with $\lambda_{f}$.

\section{Discussions}

The zonation method presented above can be applied for limits other than those presented, which are calibrated for the Swiss codes (Lateltin et al., 1997; Raetzo et al., 2002). Using an energy threshold and a return period limit, a mapping can be performed in order to estimate loss for a given period in a risk analysis. For instance one could draw a hazard map corresponding to a 1000 year return period event with a $45000 \mathrm{~kJ}$ energy (block of $\sim 4 \mathrm{~m}$ diameter $(10000 \mathrm{~kg}$ ) with a velocity of $30 \mathrm{~m} / \mathrm{s}$ ) on a $10 \mathrm{~m}$ large building. A house reached by such a block will be completely destroyed (damage $100 \%$ ). The risk can be evaluated on the base of that map.

Several issues are linked to the quality of rockfalls simulations and required data. In order to obtain accurate results, the trajectographic results have to be calibrated to field observations (Labiouse et al., 2001). The reliability of the results is obtained by a great number of trajectory simulations, more than 10000 , in order to obtain enough data to infer statistical parameters. The rock-mass volume distribution must be carefully characterized because it affects the number and volume of blocks, the energies along the rockfall trajectories and consequently the positions of the limits of the zoning. Furthermore the rebound characteristics often vary depending on the rock mass (Labiouse et al., 2001). The precision of the DEM for 3D simulations must be taken into account

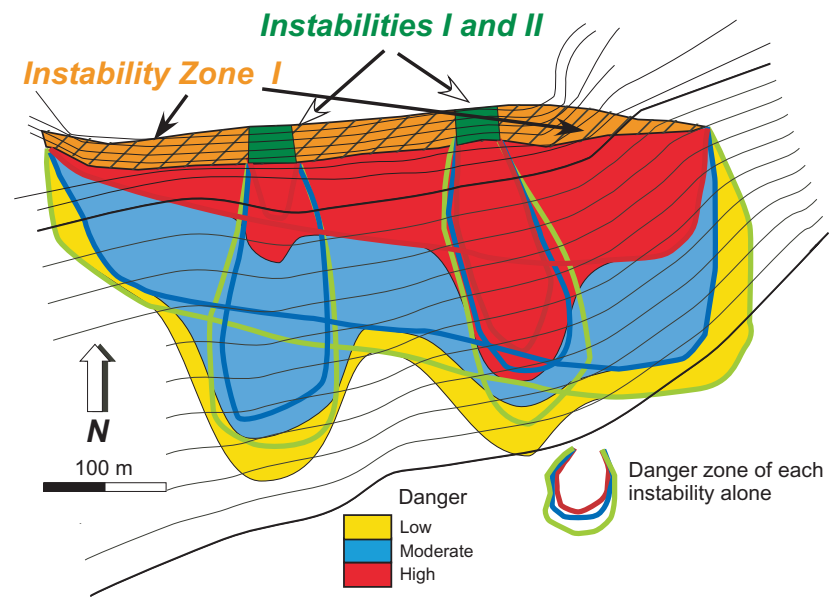

Fig. 10. Effect of overlapping danger zones from several instabilities. The frequencies of event are summed.

because it strongly controls the spreading of trajectories in space (Agliardi and Crosta, 2003).

The following remarks can be made for working out of Swiss danger maps. The extent of the yellow zone is not directly dependent on the energy. Indeed it is based on the distribution of the runout limits and on $t_{r e f}=300$ years (point 2 in Fig. 1), which leads to the most distant limit from the sources. For the red zone, only points 7 and 3 have to be considered (Fig. 1), because point 7 leads always to a larger red zone than point 5 or 6 . The choice between points 3 and 7 depends on the shape of the energy runout distribution. This is also true for the blue zone, (point 1 or 4). Note that the blue zone can disappear for large blocks. The maximum extension of the danger zone as shown on Fig. 12 is often jagged (Guzzetti et al., 2002), therefore it is not possible to create a danger zone following the external limits delineated by rockfall simulations. It can be achieved by hand contouring.

As mentioned we have chosen to infer zoning with a decrease of danger downward slopes. It is relatively easy to solve this problem in $2 \mathrm{D}$, but in $3 \mathrm{D}$ some rules have to be developed, because the danger zone of higher degree red zone can be located in the slope and disconnected from the source area. To respect the rule of decreasing danger degree down the slope, the source area has to be connected to the red zone inferred by simulations and the zones of lower danger degree (blue and yellow) have to be adapted to such modifications. If decrease of the degree of danger down slope is recommended for land-use planning, it is not necessary to use this rule in the case of the design of protection works or for a simple risk analysis.

Note that the proposed zoning methodology leads to equivalent results if the expression $P_{p}=1 /\left(\lambda_{f} \times t_{r e f} \times N_{b}\right)$ remains constant. Such a case of similar hazard zoning is observed in Fig. 9 for couples $\left(\lambda_{f}=1 / 65\right.$ years; $N_{b}=10$ and $\lambda_{f}=1 / 200$ years; $N_{b}=30$ ). 


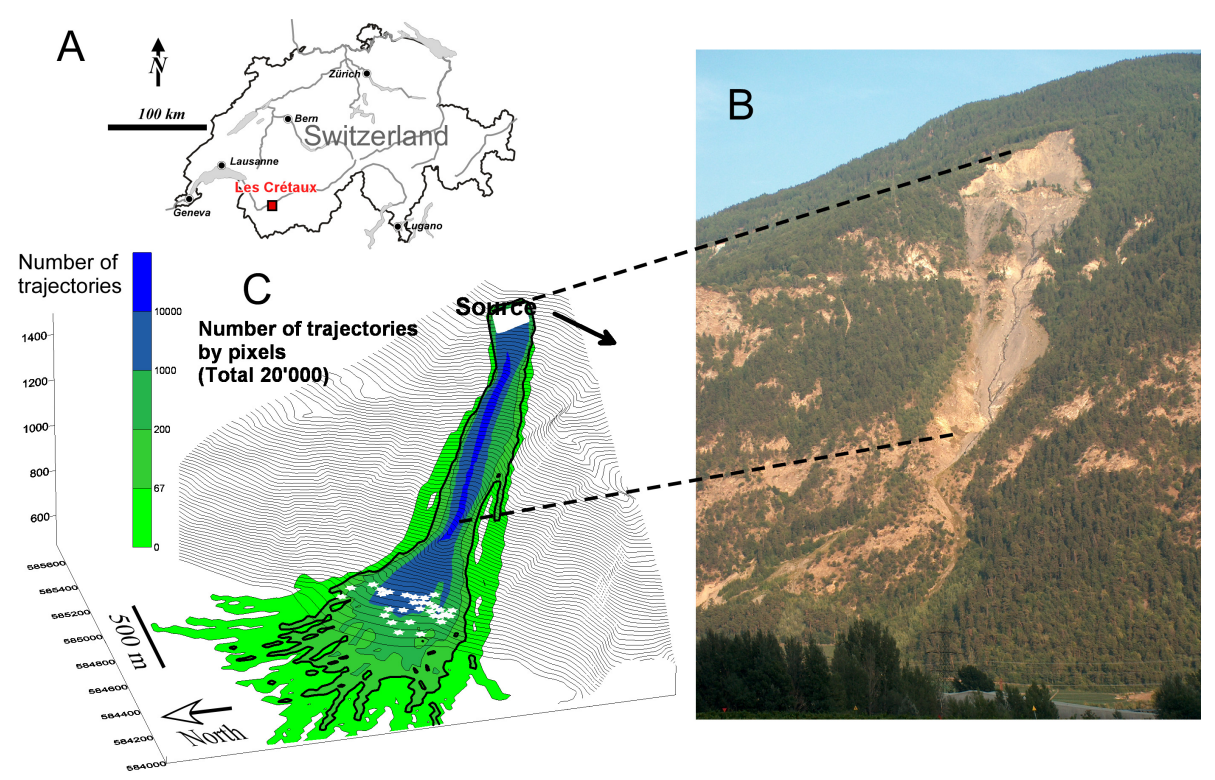

Fig. 11. (a) Location and picture (b) of Les Crétaux landslide. (c) Mapping of the number of trajectories, $N_{t r}$, by cells (pixels) of $25 \times 25 \mathrm{~m}$. The white stars indicate the observed runout end points (DTM reproduced with the permission of Swiss Federal Service of the Topography, BA034918).
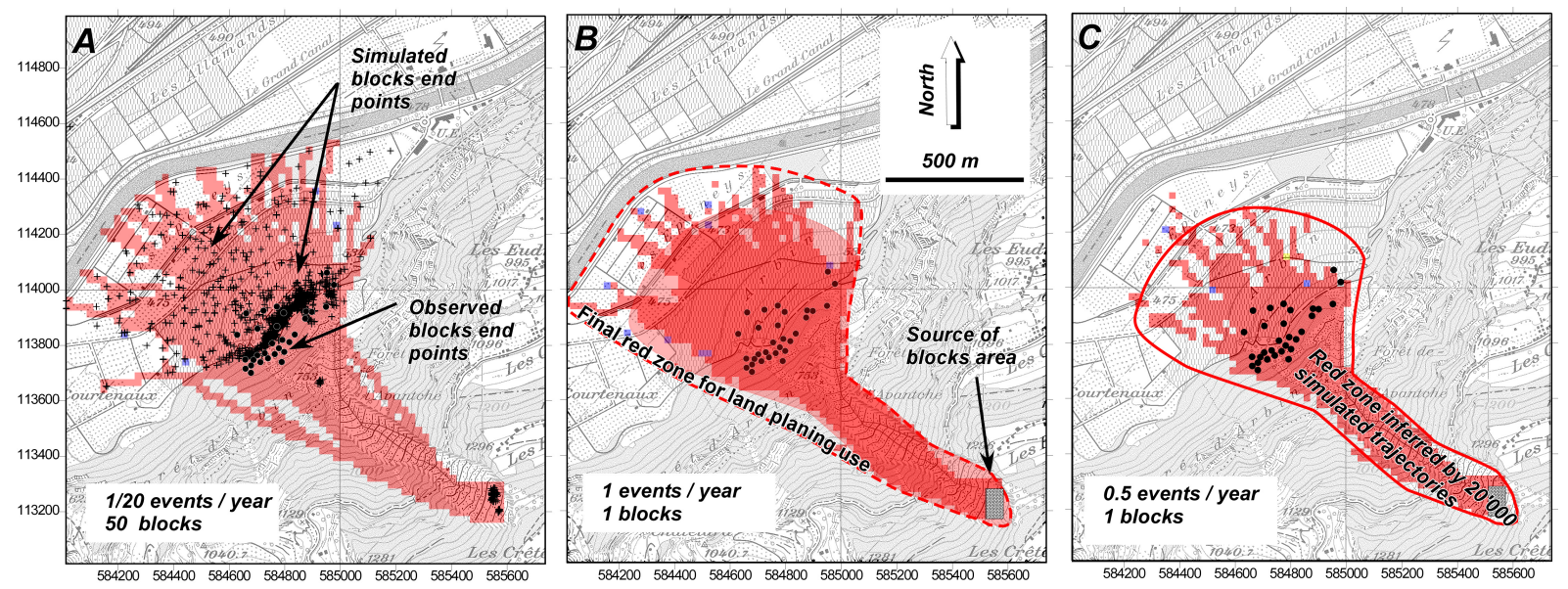

Fig. 12. Three different zoning results for les Crétaux landslide following the Swiss recommendations based on $200003 \mathrm{D}$ simulated trajectories calculated with the program EBOUL (see Fig. 11 for simulation results and location). The zonings are mostly red because of the mass of the blocks only few pixels are blue or yellow pixel. (a) $\lambda_{f}=1 / 20$ and $N_{b}=50$, (b) $\lambda_{f}=1$ and $N_{b}=1$. Two example of land planning use are indicated. The red dashed line indicates the envelope of trajectories within the energy travel limits whether the second (light red) is a solution that does not take into account to narrow energy travel limits zone which is in agreement with the solution (c); (c) $\lambda_{f}=0.5$ and $N_{b}=1$, the red line indicate the second interpretation of results in (b) that is compatible with this solution, taking into account the cells size $(25 \times 25 \mathrm{~m})$ this solution is the most appropriate in terms of landplaning (Topography reproduced with the permission of Swiss Federal Service of the Topography, BA034918).

The target size also has an effect on zoning. For instance, cells one half the length of another will contain at least $1 / 2$ of the trajectories thereby diminishing the $P_{p}$ value. Therefore, the same danger limits will be located farther up the slope. For true 3D zoning, the size of the target (including the diameter of block) is given by the size of the cells of the DEM. For pseudo-3D zoning, the target size and the size of blocks are variables that control the zoning limits explicitly.
The danger limits will migrate according to the shape of the distribution of the energy travel limits. In 3D the use of square cells for computation produces results that depend on the relative orientation of the rockfall regarding the orientation of cells. A possible improvement would be to calculate $N_{t r}(m, n)$ for a cell by counting trajectories crossing a circular area of the cell with a radius corresponding to the half target size plus the mean radius of the block. This procedure has yet to be implemented. 
We must keep in mind that changing the size of the DEM cells (assumed target), as in the example of les Crétaux, would lead to different contours. Thus to be fully compatible with the Swiss codes of practice concerning hazard mapping, the methodology presented in the paper should be improved, in order to obtain more homogeneous results in particular independent of the target size and shape. The effect of the DEM size on $N_{t r}(n, m)$ could for instance be removed by normalizing the results by unit of surface area.

But the precision of the map can not be beyond the definition of the used DEM. For instance using the Swiss codes (Lateltin et al., 1997; Raetzo et al., 2002), the energy thresholds are so close that they can lead to a single red zone when the blocks involved in the rockfalls are large (their energies are great and decrease very rapidly).

\section{Conclusions}

Three-dimensional hazard or danger zonation depends on target dimension and block size. Applying 2D zoning is not straightforward depending on the geometry of the slope. 2D zoning is only directly applicable, taking into account the target dimension, for infinite linear cliffs with homogeneous underlying slopes. Danger zoning for nearly point-source instabilities is more complicated and depends not only on the target dimension but also on the morphology of the slope: e.g. circular scree fan against planar slopes. Inspection of the geometry of pseudo-3D zoning permits an estimate of the extent of the danger zone by varying factors such as target dimension, block size, frequency of events, number of blocks or lateral distribution.

It must also be pointed out that zoning patterns based on 3D simulations have to be smoothed because of the irregular shape of the simulated trajectories. The scenarios are sensitive to the number of events and blocks per event and on $P_{p}$ distribution in space. Such parametric studies are very useful to land-use planning, because it is a unique tool to evaluate danger, hazard, and finally risk.

Acknowledgements. The authors wish to thank the Swiss Canton de Vaud authorities and the Cantonal Fire Insurance for having financed this research and authorized the publication of its results. The first author also thanks the Société Académique Vaudoise for its grant. P. Budetta from Department of Geotechnical Engineering, in University of Naples "Federico II" and E. L. Harp from USGS, Denver are warmly thanked for their detailed review, which greatly improved the manuscript. We also wish to thank C. Levesque for proofreading the manuscript and improving the English.

Edited by: P. Reichenbach

Reviewed by: P. Budetta and E. L. Harp

\section{References}

Agliardi, F. and Crosta, G.: High resolution three-dimensional numerical modelling of rockfalls, Int. J. Rock Mechanics and Mining Sci., 40, 455-471, 2003.

Baillifard, F., Jaboyedoff, M. Rouiller, J. D., and Tosoni, D.: Matterock, in: Programme Interreg IIc - "Falaises", Prévention des mouvements de versants et des instabilités de falaises, edited by: Carere, K., Ratto, S., and Zanolini, F., 79-96, 2001.

Baillifard, F., Jaboyedoff, M., Rouiller, J.-D., Couture, R., Locat, J., Locat, P., Robichaud, G., and Hamel, G.: Towards a GIS-based hazard assessment along the Quebec City Promontory, Quebec, Canada, in: Landslides Evaluation and stabilization, edited by: Lacerda, W. A., Ehrlich, M., Fontoura, A. B., and Sayo A., Balkema, 207-213, 2004.

Besson, L., Durville, J.-L., and Garry, G.: Plans de prévention des risques naturels prévisibles (PPR) Mouvements de terrain, Guide méthodologique. Ministère Equipement Transports et Logement, La Documentation française. 1999.

Bunce, C., Cruden, D., and Morgenstern, N. R.: Assessment of the hazard from rock fall on a highway, Canadian Geotechnical Journal, 34, 344-356, 1997.

Calcaterra, D., de Luca Tupputi Schinosa, F., and Fenelli, G. B.: Rockfall hazard at Mt. San Costanzo (Sorrento Peninsula, Italy), in: Landslides Evaluation and stabilization edited by: Lacerda, W. A., Ehrlich, M., Fontoura, A. B., and Sayo, A., Balkema, 265-271, 2004.

Cancelli, A, and Crosta, G.: Hazard risk assessment in rockfall prone areas, in: Proceedings conference on risk and reliability in ground engineering, edited by: Skip, B. O., Thomas Telfors, London, 177-190, 1993.

Crosta, G., Frattini, P., and Sterlacchini, S.: Valutazione e gestione del rischio da frana, Regione Lombardia, Milano, 2001.

Descoeudres, F.: L'éboulement des Crétaux, Aspects géotechniques et calcul dynamique des chutes de blocs, Publ. Soc. Suisse de Mécanique des Sols et des Roches, 121, 19-25, 1990.

Descoeudres, F. and Zimmermann, Th.: Three-dimensional dynamic calculation of rockfalls, in Proceedings 6th International Congress of Rock Mechanics, Montreal, Canada, 337-342, 1987.

Dudt, J. P. and Heidenreich, B.: Treatment of uncertainty in a threedimensional numerical simulation model for rock falls, in: International Conference on Landslides, impacts and countermeasures, edited by: Kühne, M., Einstein, H. H., Krauter, E., Klapperich, H., and Pötter, R., 507-514, 2001.

Dussauge, C., Grasso, J.-R., and Helmstetter, A.: Statistical analysis of rockfall volume distributions: Implications for rockfall dynamics, J. Geophys. Res., 108, B6, 2286, doi:10.1029/2001JB000650, 2003.

Evans, S. G. and Hungr, O.: The assessment of rockfall hazard at the base of talus slopes, Canadian Geotechnical Journal, 30, 620 636, 1993.

Feynman, R. P., Leighton, R. B., and Sands, M.: The Feynman Lectures in Physics, Addison-Wesley, 1963.

Guzzetti, F. and Crosta, G.: Programma Stone: Un programma per la simulazione tridimensionale delle cadute massi, in: Programme Interreg IIc - "Falaises", Prévention des mouvements de versants et des instabilités de falaises, edited by: Carere, K., Ratto, S., and Zanolini, F., 70-79, 2001.

Guzzetti, F., Crosta G., Detti R. and Agliardi, F.: STONE: a computer program for the three-dimensional simulation of rock-falls Computers \& Geosciences, 28, 1079-1093, 2002. 
Hoek, E.: Rock engineering, Rocsciences, 2000.

Jaboyedoff, M. and Labiouse, V.: Méthodologie: Instabilités rocheuses. Annexes au rapport final CADANAV, in: Projet CADANAV: Etablissement d'une méthodologie de mise en œuvre des cartes de dangers naturels du canton de Vaud, Documents inédits EPFL-Etat de Vaud, 2002.

Jaboyedoff, M., Baillidard, F., Hantz, D., Heidenreich, B., and Mazzoccola, D.: Terminologie, in: Programme Interreg IIc "Falaises", Prévention des mouvements de versants et des instabilités de falaises, edited by: Carere, K., Ratto, S., and Zanolini, F., 48-57, 2001.

Labiouse, V., Heidenreich, B., Desvarreux, P., Viktorovitch, M., and Guillemin, P.: Etudes trajectographiques. In Programme Interreg IIc - "Falaises", Prévention des mouvements de versants et des instabilités de falaises, edited by: Carere, K., Ratto, S., and Zanolini, F., 155-211, 2001.

Lateltin, O.: Prise en compte des dangers dus aux mouvements de terrain dans le cadre des activités de l'aménagement du territoire, Recommandations, OFEFP, 1997.

Leroi, E.: Landslides hazard - risk maps at different scales: objectives, tools and developments, in: Proceedings of the 7th Int. Symp. on Landslides, Trondheim, Norway, 1, 35-51, 1996.

Lied, K.: Rockfall problems in Norway, in: Rockfall dynamics and protective work effectiveness, ISMES pubbl. No. 90, Bergamo, 1977.

Manche, Y.: Analyse spatiale et mise en place de systèmes d'information pour l'évaluation de la vulnérabilité des territoires de montagne face aux risques naturels, Thèse université de Grenoble, 2000.

Mazzoccola, D. F. and Hudson, J. A.: A comprehensive method of rock mass characterization for indicating natural slope instability, The Quarterly Journal of Engineering Geology, 29, 37-56, 1996.

Mazzoccola, D.: La methodologia RES, in: Programme Interreg IIc - "Falaises", Prévention des mouvements de versants et des instabilités de falaises, edited by: Carere, K., Ratto, S., and Zanolini, F., Confrontation des méthodes d'études des éboulements rocheux dans l'arc alpin, 79-96, 2001.

Mazzoccola, D. and Sciesa, E.: La methodologia RHAP (Rockfall Hazard Assessment Procedure, in: Programme Interreg IIc "Falaises", Prévention des mouvements de versants et des instabilités de falaises, edited by: Carere, K., Ratto, S., and Zanolini, F., 79-96, 2001.
Pauly, J.-C. and Payany, M.: Méthodologies mises en oeuvre pour la cartographie de l'aléa lié aux instabilités rocheuses sur bassin géographique. Le cas des gorges du Tarn et de la Jonte (Lozère), Bull. Lab. Ponts et Chaussées, 236, 37-57, 2002.

Raetzo, H., Lateltin, O., Bollinger, D., and Tripet, J. P.: Hazard assessment in Switzerland - Code of practice for mass movements, Bull. Eng. Geol. Env., 61, 263-268, 2002.

Roberds, W.: Estimating temporal and spatial variability and vulnerability, in: Landslide risk management, edited by: Hungr, O., Fell, R., Couture, R., and Eberhardt, E., Balkema, 129-158, 2005.

Rouiller, J. D.: L'éboulement des crétaux - Isérables - Riddes (Valais), Publication Société Suisse de Mécanique des Sols et des Roches, 121, 15-17, 1990.

Rouiller, J.-D., Jaboyedoff, M., Marro, C., Phlippossian, F., and Mamin, M.: Pentes instables dans le Pennique valaisan, Rapport final PNR31, VDF, Zürich, 239, 1998.

Sasaki, Y., Dobrev, N., and Wakizaka, Y.: The detailed hazard map of road slopes in Japan, in: Instability - Planning and management, Thomas Telford, 381-388, 2002.

Toppe, R.: Terrain models: a tool for natural hazard mapping, in: Avalanche formation, movement and effects, edited by Salm, B. and Gubler, H., International Association of Hydrological Sciences, Wallingford, UK, 162, 629-638, 1987.

Van Westen, C. J.: Geo-information tools for landslide risk assessment: an overview of recent developments, in: Landslides Evaluation and stabilization, edited by: Lacerda, W. A., Ehrlich, M., Fontoura, A. B., and Sayo A., Balkema, 39-56, 2004.

Vengeon, J.-M., Hantz, D., and Dussauge, C.: Prédictibilité des éboulements rocheux : approche probabiliste par combinaison d'études historiques et géomécaniques, Revue Française de Géotechnique, 95/96, 143-154, 2001.

Wieczorek, G. F., Morrissey, M. M., Iovine, G., and Godt, J.: Rockfall hazards in the Yosemite Valley, US Geological Survey, OpenFile Report 98/467, 8, 1998. 